\title{
PET/MRI in the Diagnosis of Hormone-Producing Pituitary Microadenoma: A Prospective Pilot Study
}

\author{
Hao Wang*1, Bo Hou*2, Lin Lu*3, Ming Feng*4 ${ }^{*}$, Jie Zang ${ }^{1}$, Shaobo Yao ${ }^{1}$, Feng Feng ${ }^{2}$, Renzhi Wang ${ }^{4}$, Fang $\mathrm{Li}^{1}$, \\ and Zhaohui Zhu ${ }^{1}$ \\ ${ }^{I}$ Department of Nuclear Medicine and Beijing Key Laboratory of Molecular Targeted Diagnosis and Therapy in Nuclear Medicine, \\ Peking Union Medical College (PUMC) Hospital, Chinese Academy of Medical Science and PUMC, Beijing, China; ${ }^{2}$ Department of \\ Radiology, PUMC Hospital, Chinese Academy of Medical Science and PUMC, Beijing, China; ${ }^{3}$ Department of Endocrinology and \\ Key Laboratory of Endocrinology of National Health and Family Planning Commission, PUMC Hospital, Chinese Academy of \\ Medical Science and PUMC, Beijing, China; and ${ }^{4}$ Department of Neurosurgery, PUMC Hospital, Chinese Academy of Medical \\ Science and PUMC, Beijing, China
}

This study was designed to evaluate the ability of PET/MRI, using ${ }^{18} \mathrm{~F}-\mathrm{FDG}$ and ${ }^{68} \mathrm{Ga}-\mathrm{DOTATATE}$ as tracers, to detect hormoneproducing pituitary microadenoma when diagnosis is difficult using MRI alone. Methods: We recruited 37 patients with elevated hormone levels, including 19 with undiagnosable primary pituitary adenoma and 18 with suspected recurrent pituitary adenoma. ${ }^{18} \mathrm{~F}-\mathrm{FDG}$ $\mathrm{PET} / \mathrm{MRI}$ and ${ }^{8} \mathrm{Ga}$-DOTATATE PET/MRI were performed within $1 \mathrm{wk}$ of each other in all patients. Within 2 wk afterward, 27 of the 37 patients underwent transsphenoidal adenomectomy, 3 underwent sella region radiotherapy, 1 underwent somatostatin therapy, and 6 had only clinical follow-up. The image characteristics and uptake levels were correlated with the surgical findings and pathologic results. Receiver-operating-characteristic curves were analyzed to determine the optimal cutoff to differentiate adenoma from normal pituitary tissue. The area under the receiver-operating-characteristic curve was calculated to compare diagnostic performance. Results: The PET/MR images were of diagnostic quality and without obvious image artifacts. The high contrast of the PET images provided complementary information to the fine anatomic display of the MR images. Increased ${ }^{18} \mathrm{~F}-\mathrm{FDG}$ uptake was clearly observed in all patients. MRI enhanced using a $0.05 \mathrm{mmol} / \mathrm{kg}$ dose of gadopentetate dimeglumine showed suggestive findings in only $47 \%$ of the patients with primary adenoma and $39 \%$ of those with recurrent adenoma; when a $0.1 \mathrm{mmol} / \mathrm{kg}$ dose was used, the respective percentages were $37 \%$ and $50 \%$. The ${ }^{18} \mathrm{~F}$-FDG SUV max $_{\text {max }}$ of the 16 primary adenomas that underwent transsphenoidal adenomectomy $(6.8 \pm 3.7)$ was significantly higher than that of normal pituitary tissue $(3.2 \pm 1.1, P<0.01)$. The adenomas showed moderate ${ }^{68} \mathrm{Ga}$-DOTATATE uptake (SUV $\max$, $3.8 \pm 2.6$ ), but the ${ }^{68} \mathrm{Ga}$-DOTATATE uptake was generally lower than that of normal pituitary tissue $\left(\mathrm{SUV}_{\max }, 6.2 \pm 3.2, P<0.05\right)$. In the 11 suspected recurrent pituitary adenomas that underwent transsphenoidal adenomectomy, the ${ }^{18} \mathrm{~F}-\mathrm{FDG} \mathrm{SUV}_{\max }$ was $6.1 \pm 3.5$, significantly higher than that of normal pituitary tissue $(2.5 \pm 1.1$, $P<0.01)$, and the ${ }^{68} \mathrm{Ga}-\mathrm{DOTATATE}$ SUV $_{\max }$ was $3.0 \pm 1.1$, significantly lower than that of normal pituitary tissue $(5.5 \pm 1.7, P<0.01)$. The ${ }^{18} \mathrm{~F}-\mathrm{FDG} /{ }^{68} \mathrm{Ga}$-DOTATATE SUV $\mathrm{V}_{\max }$ ratio of the adenomas $(2.3 \pm$ 1.5) was significantly higher than that of normal pituitary tissue

Received Feb. 16, 2017; revision accepted Jul. 10, 2017.

For correspondence or reprints contact: Zhaohui Zhu, Peking Union Medical College (PUMC) Hospital, Chinese Academy of Medical Science and PUMC, No. 1 Shauaifu Yuan, Wangfujing St., Dongcheng District, Beijing, 100730, China.

E-mail: zhuzhh@pumch.cn

${ }^{\star}$ Contributed equally to this work.

Published online Aug. 3, 2017.

COPYRIGHT (C 2018 by the Society of Nuclear Medicine and Molecular Imaging.
$(0.6 \pm 0.3, P<0.05)$. When the ${ }^{18} \mathrm{~F}-\mathrm{FDG} \mathrm{SUV}_{\max }$ alone and the ${ }^{18} \mathrm{~F}-\mathrm{FDG} /{ }^{68} \mathrm{Ga}-\mathrm{DOTATATE}$ SUV $\max$ ratio were used as criteria to discriminate between adenoma and pituitary tissue, the best analysis came from the ratio, and that from ${ }^{18} \mathrm{~F}-\mathrm{FDG}$ SUV $\max$ alone was slightly less, with optimal diagnostic cutoffs of 1.04 and 3.88 , respectively. Conclusion: PET/MRI provides an ideal tool for the detection of hormone-producing pituitary microadenoma. Dual-tracer ${ }^{18} \mathrm{~F}-\mathrm{FDG}$ and ${ }^{68} \mathrm{Ga}-\mathrm{DOTATATE}$ PET/MRI was useful for distinguishing pituitary microadenoma from normal pituitary tissue.

Key Words: pituitary adenoma; ${ }^{68} \mathrm{Ga}-\mathrm{DOTATATE} ;{ }^{18} \mathrm{~F}-\mathrm{FDG}$; PET/ MRI

J Nucl Med 2018; 59:523-528

DOI: 10.2967/jnumed.117.191916

$\mathbf{P}$ ituitary adenoma accounts for about $10 \%-20 \%$ of all primary intracranial tumors (1). These tumors can cause symptoms either through a mass effect or through oversecretion of various hormones. Hypersecretion of hormones from the pituitary gland leads to syndromes such as hyperprolactinemia, Cushing disease, and acromegaly. MRI has been the first choice for detecting pituitary adenoma since the 1990s (2). However, sometimes MRI struggles to detect adenoma, especially when the lesion is small or when the anatomic conditions have been altered by surgery (3-6).

${ }^{18}$ F-FDG PET has a high sensitivity for the detection of pituitary adenoma $(7,8)$. Somatostatin receptors are expressed by both normal pituitary tissue and pituitary adenoma. Novel ${ }^{68} \mathrm{Ga}$-labeled somatostatin analogs such as ${ }^{68} \mathrm{Ga}$-DOTATATE are now finding increasing clinical application (9-14). Previously, we reported that ${ }^{68} \mathrm{Ga}$-DOTATATE in general had a higher uptake in normal pituitary tissue than in recurrent or residual adenoma. However, there was significant overlap in uptake between these 2 entities, making it difficult to distinguish adenoma from normal pituitary tissue using solely this tracer. The combined analysis of ${ }^{68} \mathrm{Ga}$-DOTATATE and ${ }^{18}$ F-FDG PET/CT might therefore be of clinical value in differentiating recurrent or residual pituitary adenoma from normal pituitary tissue (15). Furthermore, combined assessment using PET is advantageous because brain CT scanning is a less sensitive method and cannot accurately detect regions of increased tracer uptake in the pituitary gland. 
Integrated PET/MRI has recently become commercially available and offers many advantages in the evaluation of brain disease. However, its utility in the evaluation of pituitary lesions has not been systematically explored. In this prospective pilot study, patients with suspected functional pituitary adenoma (for which diagnosis by MRI alone was difficult) underwent dual-tracer ${ }^{18} \mathrm{~F}-\mathrm{FDG}$ and ${ }^{68} \mathrm{Ga}-$ DOTATATE brain PET/MRI to evaluate its possible application for the detection of hormone-producing pituitary microadenoma.

\section{MATERIALS AND METHODS}

\section{Patients}

This was a prospective pilot study with Institutional Review Board approval and written informed consent from the patients enrolled. The total enrollment was 37 patients (11 men, 26 women; mean age $\pm \mathrm{SD}$, $34 \pm 15 \mathrm{y})$. The patients had elevated hormone levels, including adrenocorticotropic hormone $(n=33)$, growth hormone $(n=3)$, or thyroid-stimulating hormone $(n=1)$. All patients were suspected to have a pituitary microadenoma, including 19 patients with possible primary tumors and 18 patients with recurrent tumors. All patients had undergone contrast-enhanced 3-T MRI before recruitment. The MRI protocols included 3 serial sequences: a coronal T2-weighted fast spin echo sequence (repetition time [TR], 3,660 ms; echo time [TE], 97.3 $\mathrm{ms}$; field of view [FOV], $20 \times 16 \mathrm{~cm}$; slice thickness, $4 \mathrm{~mm}$; slice spacing, $1 \mathrm{~mm}$; matrix, $320 \times 224$ ), a coronal T1-weighted fast spin echo sequence (TR, $417 \mathrm{~ms}$; TE, $8.7 \mathrm{~ms}$; FOV, $20 \times 16 \mathrm{~cm}$; slice thickness, $3 \mathrm{~mm}$; slice spacing, $0.6 \mathrm{~mm}$; matrix, $320 \times 224$ ), and a sagittal T1-weighted Cube sequence (a GE Healthcare fast spin echo sequence) (TR, $300 \mathrm{~ms}$; TE, $15.1 \mathrm{~ms}$; FOV, $16 \times 16 \mathrm{~cm}$; slice thickness, $3 \mathrm{~mm}$; no slice spacing; matrix, $224 \times 192$ ). Fat saturation was applied. The MRI protocols also included a dynamic coronal T1-weighted fast spin echo sequence (TR, $250 \mathrm{~ms}$; TE, $12.6 \mathrm{~ms}$; FOV, $20 \times 16 \mathrm{~cm}$; slice thickness, $2 \mathrm{~mm}$; slice spacing, $0.5 \mathrm{~mm}$; matrix, $256 \times 192$; 4 slices to cover the pituitary; $28 \mathrm{~s} /$ phase; scanning time, $2 \min 54 \mathrm{~s}$ ). A 0.05 $\mathrm{mmol} / \mathrm{kg}$ bolus of the contrast agent gadopentetate dimeglumine was administered by a power injector at a rate of $3 \mathrm{~mL} / \mathrm{s}$. Afterward, coronal and sagittal T1-weighted imaging were repeated. Among the 37 patients, 16 had undiagnosable MRI findings and 21 had negative MRI results. Both ${ }^{18} \mathrm{~F}$-FDG PET/MRI and ${ }^{68} \mathrm{Ga}$-DOTATATE PET/MRI were performed within $1 \mathrm{wk}$ of each other in all patients. Within $2 \mathrm{wk}$ afterward, 27 patients underwent transsphenoidal adenomectomy (Table 1), whereas because of surgical difficulty or other reasons, 3 patients underwent sella region radiotherapy, 1 patient underwent somatostatin therapy, and the other 6 patients had clinical follow-up only. The latter 10 patients were excluded from further analysis.

\section{PET/MRI}

Brain PET/MR images were acquired with the patient supine $1 \mathrm{~h}$ after intravenous injection of either $370 \mathrm{MBq}$ of ${ }^{18} \mathrm{~F}-\mathrm{FDG}$ or $120-200$ $\mathrm{MBq}$ of ${ }^{68} \mathrm{Ga}$-DOTATATE. These 2 different PET/MRI scans were performed on separate days within 1 wk of each other. The images were acquired using a Signa time-of-flight PET/MRI system (GE Healthcare). Simultaneous PET and 3-T MRI data were acquired. Four MRI sequences were performed. The first was coronal and sagittal T2weighted fast spin echo imaging (TR, 3,000 ms; TE, 98 ms; FOV, $18 \times$ $18 \mathrm{~cm}$; slice thickness, $3 \mathrm{~mm}$; no slice spacing; frequency encoding, 320) with fat saturation applied to inhibit the hyperintensity of the cranial base, as well as periodically rotated overlapping parallel lines with enhanced reconstruction to ensure excellent image quality. The second sequence was coronal T1-weighted Cube imaging (TR, 365 $\mathrm{ms}$; TE, $15 \mathrm{~ms}$; FOV, $16 \times 16 \mathrm{~cm}$; slice thickness, $3 \mathrm{~mm}$; no slice spacing; matrix, $224 \times 224$ ) with interplane interpolation applied to achieve a $1.5-\mathrm{mm}$ slice thickness. The third sequence was sagittal T1weighted Cube imaging (TR, $400 \mathrm{~ms}$; TE, $15 \mathrm{~ms}$; FOV, $16 \times 16 \mathrm{~cm}$; slice thickness, $2 \mathrm{~mm}$; no slice spacing; matrix, $224 \times 192$ ) with interplane interpolation applied to achieve a 1-mm slice thickness. Fat saturation was applied. The fourth sequence was dynamic coronal T1-weighted fast spin echo imaging (TR, $360 \mathrm{~ms}$; TE, $9 \mathrm{~ms}$; FOV, $17 \times$ $15.3 \mathrm{~cm}$; slice thickness, $2 \mathrm{~mm}$; slice spacing, $0.5 \mathrm{~mm}$; matrix, $224 \times$ $160 ; 10$ slices to cover the whole region; $19 \mathrm{~s} /$ phase; scanning time, $3 \mathrm{~min} 6 \mathrm{~s}$ ). A $0.1 \mathrm{mmol} / \mathrm{kg}$ bolus of the contrast agent gadopentetate dimeglumine was administered by a power injector at a rate of $3 \mathrm{~mL} / \mathrm{s}$. Afterward, coronal and sagittal fat-saturation Cube T1-weighted imaging (TR, $400 \mathrm{~ms}$; TE, $15 \mathrm{~ms}$; FOV, $16 \times 16 \mathrm{~cm}$; slice thickness, $1.4 \mathrm{~mm}$; no slice spacing; matrix, $224 \times 192$; scanning time, $5 \mathrm{~min}$ and $30 \mathrm{~s}$ ) was also performed, with a voxel size of $0.3 \times 0.3 \times 0.7 \mathrm{~mm}$ after interpolation. All sequences in this examination covered the whole sellar region, including the right and left cavernous sinuses. For this integrated PET/MRI scan, the attenuation correction was performed with T1-weighted imaging, which may be affected by the gadopentetate; thus, the PET acquisition was performed before and after contrast injection. The duration was about $20 \mathrm{~min}$ for each task.

MR images were assessed by 2 experienced neuroradiologists, who were masked to the clinical and PET data. The ${ }^{18} \mathrm{~F}-\mathrm{FDG}$ and ${ }^{68} \mathrm{Ga}-$ DOTATATE PET/MRI studies were reviewed for regions of increased uptake by 2 board-certified specialists in nuclear medicine, who were masked to the clinical data independently. The pattern of uptake and the $\mathrm{SUV}_{\text {max }}$ were documented. The image characteristics and uptake levels were correlated with the surgical findings and pathologic results.

\section{Statistical Analysis}

Quantitative results were expressed as the mean \pm SD. Differences between 2 independent groups were determined by a Student $t$ test. Receiver-operating-characteristic (ROC) curves were analyzed to determine the optimal cutoff for detecting adenoma and normal pituitary tissue. All statistical tests were 2-tailed, and a $P$ value of less than 0.05 was considered statistically significant. SPSS software (version 23.0; IBM) was used for statistical analyses.

\section{RESULTS}

\section{Image Quality}

The PET/MRI system provided diagnostic image quality without apparent image artifacts. Most lesions demonstrated high ${ }^{18}$ F-FDG uptake (Fig. 1 and Supplemental Fig. 1; supplemental materials are available at http://jnm.snmjournals.org). Moreover, the different MRI sequences available with high resolution facilitated evaluation of the images provided by the PET/MRI system.

\section{Detection of Primary Adenoma}

When a $0.05 \mathrm{mmol} / \mathrm{kg}$ dose of MRI contrast medium was used, $9(47 \%)$ of the 19 patients with a possible primary adenoma had undiagnosable lesions that were suspected to show low enhancement, and the other 10 patients had negative findings. When a 0.1 $\mathrm{mmol} / \mathrm{kg}$ dose was used, 7 (37\%) of the 19 patients had lesions that definitely showed low enhancement, and the other 12 patients had negative findings. Increased ${ }^{18} \mathrm{~F}$-FDG uptake was present in all 19 patients. The results of dynamic contrast-enhanced MRI and ${ }^{18}$ F-FDG PET were comparable and therefore acted to validate each other, thus increasing diagnostic confidence.

The ${ }^{18} \mathrm{~F}-\mathrm{FDG} \mathrm{SUV}_{\max }$ of the 16 primary adenomas that underwent transsphenoidal adenomectomy was $6.8 \pm 3.7$, significantly higher than that of normal pituitary tissue $(3.2 \pm 1.1, P<0.01)$. In contrast, the ${ }^{68} \mathrm{Ga}$-DOTATATE SUV max $_{\text {max }}$ of these 16 adenomas was $3.8 \pm 2.6$, significantly lower than that of normal pituitary tissue $(6.2 \pm 3.2, P<0.05)$. In each case, the location of the adenoma on PET/MRI corresponded with its location on surgery (Table 1). 
TABLE 1

Patient Characteristics

\begin{tabular}{|c|c|c|c|c|c|c|c|c|c|c|}
\hline \multirow{2}{*}{$\begin{array}{l}\text { Patient } \\
\text { no. }\end{array}$} & \multirow{2}{*}{$\begin{array}{l}\text { Age } \\
(y)\end{array}$} & \multirow[b]{2}{*}{ Sex } & \multirow[b]{2}{*}{$\mathrm{P} / \mathrm{R}$} & \multirow{2}{*}{$\begin{array}{l}\text { Hormone } \\
\text { level }\end{array}$} & \multicolumn{2}{|c|}{ MRI result } & \multicolumn{2}{|c|}{ PET/MRI SUV $\max$} & \multirow{2}{*}{$\begin{array}{l}\text { Adenoma } \\
\text { size }(\mathrm{mm})\end{array}$} & \multirow{2}{*}{$\begin{array}{l}\text { Immunohistochemical } \\
\text { staining result }\end{array}$} \\
\hline & & & & & Half dose & Full dose & ${ }^{18} \mathrm{~F}-\mathrm{FDG}$ & ${ }^{68} \mathrm{Ga}-\mathrm{DOTATATE}$ & & \\
\hline 1 & 31 & $\mathrm{~F}$ & $P$ & $\mathrm{ACTH} \uparrow, \mathrm{F} \uparrow$ & - & + & 7.56 & 2.83 & $6 \times 5 \times 5$ & $\mathrm{ACTH}+, \mathrm{GH}+, \mathrm{LH}+$ \\
\hline 2 & 16 & $\mathrm{M}$ & $P$ & $\mathrm{ACTH} \uparrow, \mathrm{F} \uparrow$ & - & + & 4.8 & 2.8 & $5 \times 5 \times 5$ & $\mathrm{ACTH}+, \mathrm{GH}+$ \\
\hline 3 & 26 & $\mathrm{~F}$ & $P$ & $\mathrm{ACTH} \uparrow, \mathrm{F} \uparrow$ & - & - & 3.1 & 2.09 & $8 \times 3 \times 3$ & $\mathrm{ACTH}+, \mathrm{GH}+$ \\
\hline 4 & 63 & $\mathrm{~F}$ & $\mathrm{P}$ & $\mathrm{GH} \uparrow, \mathrm{IGF} 1 \uparrow$ & - & - & 10.21 & 5.23 & $7 \times 5 \times 5$ & $\mathrm{ACTH}+, \mathrm{GH}+, \mathrm{LH}+, \mathrm{PRL}+$ \\
\hline 5 & 38 & $\mathrm{~F}$ & $\mathrm{P}$ & $\mathrm{ACTH} \uparrow, \mathrm{F} \uparrow$ & - & - & 4.81 & 1.24 & $5 \times 4 \times 3$ & $\mathrm{ACTH}+$ \\
\hline 6 & 38 & $\mathrm{~F}$ & $P$ & $\mathrm{ACTH} \uparrow, \mathrm{F} \uparrow$ & - & - & 9.07 & 4.61 & $5 \times 4 \times 3$ & $\mathrm{ACTH}+$ \\
\hline 7 & 16 & $\mathrm{M}$ & $P$ & $\mathrm{ACTH} \uparrow, \mathrm{F} \uparrow$ & \pm & + & 6.81 & 5.3 & $6 \times 5 \times 5$ & $\mathrm{ACTH}+, \mathrm{GH}+, \mathrm{LH}+$ \\
\hline 8 & 28 & $\mathrm{~F}$ & $\mathrm{P}$ & $\mathrm{ACTH} \uparrow, \mathrm{F} \uparrow$ & \pm & + & 2.95 & 12.05 & $3 \times 3 \times 2$ & $\mathrm{ACTH}+, \mathrm{GH}+, \mathrm{LH}+$ \\
\hline 9 & 63 & $M$ & $\mathrm{P}$ & $\mathrm{ACTH} \uparrow, \mathrm{F} \uparrow$ & \pm & - & 7.23 & 2.55 & $5 \times 5 \times 5$ & $\mathrm{ACTH}+, \mathrm{GH}+, \mathrm{LH}+$ \\
\hline 10 & 26 & $\mathrm{M}$ & $\mathrm{P}$ & $\mathrm{ACTH} \uparrow, \mathrm{F} \uparrow$ & \pm & - & 3.68 & 6.15 & $3 \times 2 \times 2$ & $\mathrm{ACTH}+, \mathrm{GH}+, \mathrm{LH}+$ \\
\hline 11 & 17 & M & $P$ & $\mathrm{ACTH} \uparrow, \mathrm{F} \uparrow$ & \pm & - & 17.48 & 3.35 & $10 \times 8 \times 8$ & $\mathrm{ACTH}+, \mathrm{GH}+$ \\
\hline 12 & 50 & $\mathrm{~F}$ & $\mathrm{P}$ & $\mathrm{ACTH} \uparrow, \mathrm{F} \uparrow$ & \pm & + & 3.1 & 2.09 & $5 \times 5 \times 5$ & $\mathrm{ACTH}+, \mathrm{GH}+, \mathrm{LH}+$ \\
\hline 13 & 38 & $M$ & $\mathrm{P}$ & $\mathrm{ACTH} \uparrow, \mathrm{F} \uparrow$ & - & - & 9.69 & 2.28 & $5 \times 3 \times 3$ & $\mathrm{ACTH}+, \mathrm{GH}+$ \\
\hline 14 & 45 & $\mathrm{~F}$ & $P$ & $\mathrm{ACTH} \uparrow, \mathrm{F} \uparrow$ & - & + & 5.61 & 3.02 & $5 \times 5 \times 3$ & $\mathrm{ACTH}+, \mathrm{GH}+, \mathrm{LH}+$ \\
\hline 15 & 20 & $\mathrm{~F}$ & $\mathrm{P}$ & $\mathrm{ACTH} \uparrow, \mathrm{F} \uparrow$ & \pm & - & 8.56 & 2.2 & $5 \times 5 \times 5$ & $\mathrm{ACTH}+, \mathrm{GH}+, \mathrm{LH}+$ \\
\hline 16 & 16 & $\mathrm{M}$ & $\mathrm{P}$ & $\mathrm{ACTH} \uparrow, \mathrm{F} \uparrow$ & \pm & - & 4.27 & 3.02 & $4 \times 3 \times 3$ & $\mathrm{ACTH}+, \mathrm{GH}+$ \\
\hline 17 & 20 & $\mathrm{~F}$ & $\mathrm{R}$ & $\mathrm{ACTH} \uparrow, \mathrm{F} \uparrow$ & - & + & 5.58 & 5.38 & $5 \times 5 \times 5$ & $\mathrm{ACTH}+, \mathrm{GH}+$ \\
\hline 18 & 30 & $\mathrm{~F}$ & $\mathrm{R}$ & $\mathrm{ACTH} \uparrow, \mathrm{F} \uparrow$ & - & + & 8.84 & 2.62 & $6 \times 5 \times 5$ & $\mathrm{ACTH}+, \mathrm{GH}+$ \\
\hline 19 & 25 & $\mathrm{~F}$ & $\mathrm{R}$ & $\mathrm{ACTH} \uparrow, \mathrm{F} \uparrow$ & \pm & + & 6.6 & 4.36 & $6 \times 5 \times 5$ & $\mathrm{ACTH}+$ \\
\hline 20 & 31 & $\mathrm{~F}$ & $\mathrm{R}$ & $\mathrm{ACTH} \uparrow, \mathrm{F} \uparrow$ & \pm & + & 2.69 & 1.94 & $5 \times 3 \times 3$ & $\mathrm{ACTH}-, \mathrm{FSH}+, \mathrm{GH}+, \mathrm{LH}+$ \\
\hline 21 & 29 & $\mathrm{~F}$ & $\mathrm{R}$ & $\mathrm{ACTH} \uparrow, \mathrm{F} \uparrow$ & \pm & + & 5.4 & 3.83 & $5 \times 5 \times 5$ & $\mathrm{ACTH}+, \mathrm{GH}+, \mathrm{LH}+$ \\
\hline 22 & 10 & $\mathrm{~F}$ & $\mathrm{R}$ & $\mathrm{ACTH} \uparrow, \mathrm{F} \uparrow$ & - & - & 2.49 & 2.39 & $3 \times 3 \times 3$ & $\mathrm{ACTH}+, \mathrm{GH}+, \mathrm{LH}+$ \\
\hline 23 & 45 & $\mathrm{~F}$ & $\mathrm{R}$ & $\mathrm{ACTH} \uparrow, \mathrm{F} \uparrow$ & \pm & + & 3.96 & 2.08 & $5 \times 5 \times 5$ & $\mathrm{ACTH}+, \mathrm{GH}+$ \\
\hline 24 & 35 & $\mathrm{~F}$ & $\mathrm{R}$ & $\mathrm{ACTH} \uparrow, \mathrm{F} \uparrow$ & - & - & 13.3 & 2.35 & $5 \times 5 \times 5$ & $\mathrm{ACTH}+, \mathrm{GH}+$ \\
\hline 25 & 50 & $\mathrm{~F}$ & $\mathrm{R}$ & $\mathrm{ACTH} \uparrow, \mathrm{F} \uparrow$ & - & - & 3.7 & 3.35 & $4 \times 3 \times 3$ & $\mathrm{ACTH}+$ \\
\hline 26 & 41 & $\mathrm{~F}$ & $\mathrm{R}$ & $\mathrm{ACTH} \uparrow, \mathrm{F} \uparrow$ & \pm & + & 10.49 & 2.02 & $5 \times 6 \times 6$ & $\mathrm{ACTH}+, \mathrm{GH}+$ \\
\hline 27 & 32 & $M$ & $\mathrm{R}$ & $\mathrm{ACTH} \uparrow, \mathrm{F} \uparrow$ & - & + & 3.52 & 2.81 & $5 \times 5 \times 4$ & $\mathrm{ACTH}+, \mathrm{GH}+, \mathrm{LH}+$ \\
\hline 28 & 11 & $\mathrm{~F}$ & $\mathrm{P}$ & $\mathrm{ACTH} \uparrow, \mathrm{F} \uparrow$ & - & - & 7.45 & 3.92 & NA & NA \\
\hline 29 & 51 & $M$ & $\mathrm{P}$ & $\mathrm{ACTH} \uparrow, \mathrm{F} \uparrow$ & - & + & 6.33 & 2.17 & NA & NA \\
\hline 30 & 59 & $\mathrm{~F}$ & $\mathrm{P}$ & $\mathrm{ACTH} \uparrow, \mathrm{F} \uparrow$ & \pm & - & 4.23 & 2.15 & NA & NA \\
\hline 31 & 55 & $\mathrm{~F}$ & $\mathrm{R}$ & $\mathrm{GH} \uparrow, \mathrm{IGF} 1 \uparrow$ & - & - & 5.24 & 3.31 & NA & NA \\
\hline 32 & 57 & $M$ & $\mathrm{R}$ & $\mathrm{T} 4 \uparrow$ & - & + & 7.34 & 2.35 & NA & NA \\
\hline 33 & 30 & $\mathrm{~F}$ & $\mathrm{R}$ & $\mathrm{GH} \uparrow, \mathrm{IGF} 1 \uparrow$ & - & - & 9.56 & 3.22 & NA & NA \\
\hline 34 & 34 & $\mathrm{~F}$ & $\mathrm{R}$ & $\mathrm{ACTH} \uparrow, \mathrm{F} \uparrow$ & - & - & 8.28 & 2.13 & NA & NA \\
\hline 35 & 17 & M & $\mathrm{R}$ & $\mathrm{ACTH} \uparrow, \mathrm{F} \uparrow$ & - & - & 5.21 & 3.28 & NA & NA \\
\hline 36 & 39 & $\mathrm{~F}$ & $\mathrm{R}$ & $\mathrm{ACTH} \uparrow, \mathrm{F} \uparrow$ & \pm & - & 8.35 & 5.28 & NA & NA \\
\hline 37 & 35 & $\mathrm{~F}$ & $\mathrm{R}$ & $\mathrm{ACTH} \uparrow, \mathrm{F} \uparrow$ & \pm & - & 4.38 & 3.17 & NA & NA \\
\hline
\end{tabular}

$\mathrm{P}=$ primary; $\mathrm{R}=$ recurrent; half dose $=0.05 \mathrm{mmol} / \mathrm{kg}$ dose of gadopentetate dimeglumine; full dose $=0.1 \mathrm{mmol} / \mathrm{kg}$ dose of gadopentetate dimeglumine; $\mathrm{ACTH}=$ adrenocorticotropic hormone; $\mathrm{F}=$ cortisol (compound $\mathrm{F}$ ); $\mathrm{GH}=$ growth hormone; $\mathrm{LH}=$ luteinizing hormone; IGF1 = insulinlike growth factor 1; PRL = prolactin; FSH = follicle-stimulating hormone; NA = not available because patient accepted clinical follow-up or treatments other than surgery; T4 = thyroxine; + = positive; - = negative.

\section{Detection of Recurrent Adenoma}

When a $0.05 \mathrm{mmol} / \mathrm{kg}$ dose of MRI contrast medium was used, $7(39 \%)$ of the 18 patients with a suspected recurrent adenoma had lesions that were suspected to show low enhancement. When a
$0.1 \mathrm{mmol} / \mathrm{kg}$ dose was used, $9(50 \%)$ of the 18 patients had lesions that definitely showed low enhancement. However, the dualtracer PET/MR images clearly differentiated almost all recurrent adenomas ( ${ }^{18} \mathrm{~F}$-FDG-positive, ${ }^{68} \mathrm{Ga}$-DOTATATE-positive) from 


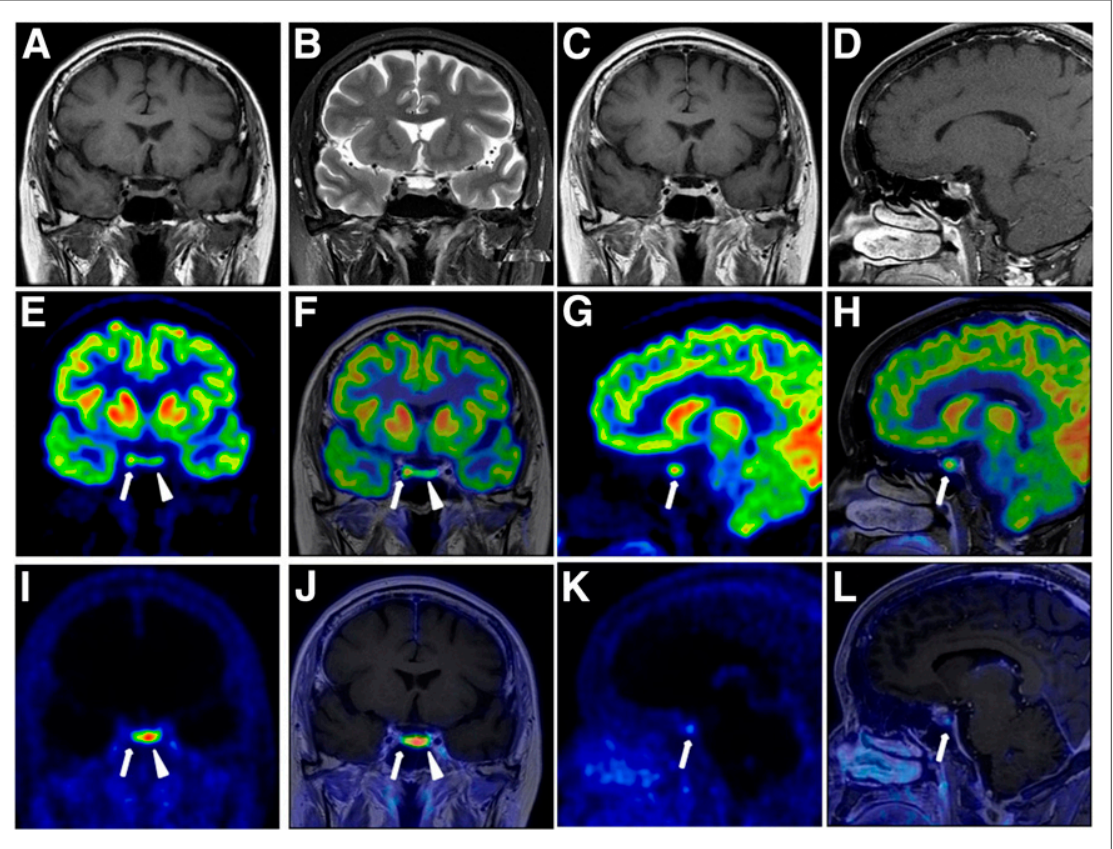

FIGURE 1. A 31-y-old woman with high adrenocorticotropic hormone level (patient 1 in Table 1). (A-D) MR images showing equivocal lesion at right end of sella region (from left to right: T1weighted coronal, T2-weighted coronal, and contrast-enhanced T1-weighted coronal and sagittal views). (E-H) ${ }^{18} \mathrm{~F}-\mathrm{FDG} \mathrm{PET} / \mathrm{MR}$ images showing definitely avid lesion (arrows) at same region as on MR images (from left to right: coronal PET, coronal PET/MRI, sagittal PET, and sagittal PET/ MRI). (I-L) ${ }^{68} \mathrm{Ga}$-DOTATATE PET/MR images showing lower uptake in lesion than in normal pituitary tissue (arrowhead) (from left to right: coronal PET, coronal PET/MRI, sagittal PET, and sagittal PET/MRI). Follow-up surgery confirmed presence of right-sided $6 \times 5 \times 5 \mathrm{~mm}$ functional pituitary microadenoma, and pathologic stains were adrenocorticotropic hormone-positive, luteinizing hormone-positive, and growth hormone-positive.

normal pituitary tissue $\left({ }^{18} \mathrm{~F}-\mathrm{FDG}-\right.$ negative, ${ }^{68} \mathrm{Ga}$-DOTATATEpositive).

The ${ }^{18}$ F-FDG $\mathrm{SUV}_{\max }$ of the 11 recurrent adenomas that underwent transsphenoidal adenomectomy was $6.1 \pm 3.5$,
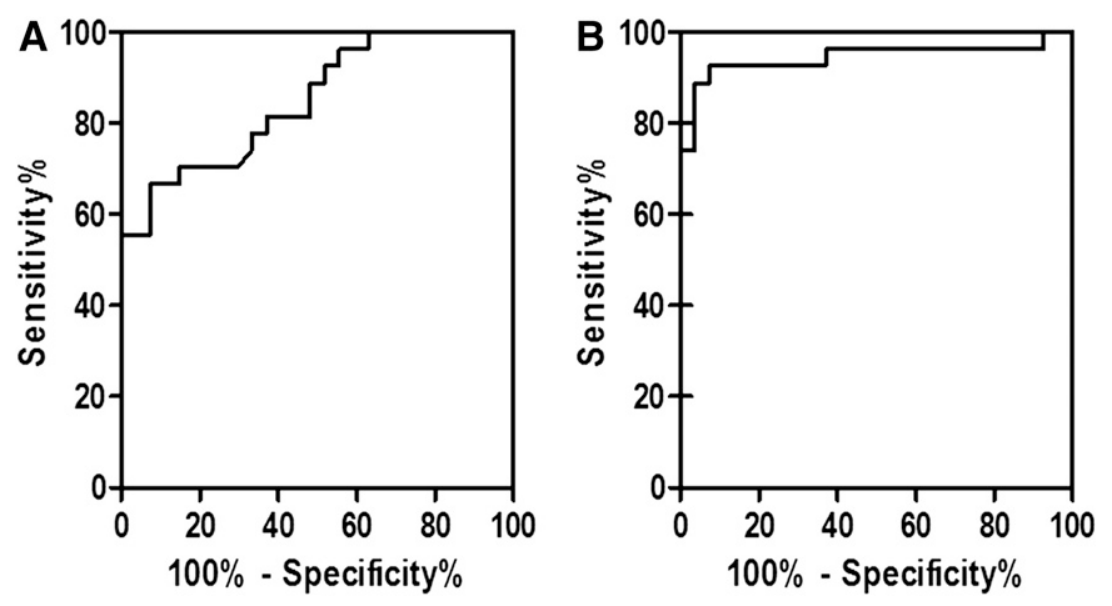

FIGURE 2. Use of ${ }^{18} \mathrm{~F}-\mathrm{FDG} \mathrm{SUV}_{\max }(\mathrm{A})$ and ${ }^{18} \mathrm{~F}-\mathrm{FDG} /{ }^{68} \mathrm{Ga}-\mathrm{DOT} A T A T E$ SUV $\max$ ratio (B) ROC curves for differentiation of pituitary adenoma from normal pituitary tissue. Area under curve and standard error were $0.85 \pm 0.05$ for ${ }^{18} \mathrm{~F}-\mathrm{FDG}$ and $0.94 \pm 0.03$ for ${ }^{18} \mathrm{~F}-\mathrm{FDG} /{ }^{68} \mathrm{Ga}-\mathrm{DOTATATE}$ Optimal diagnostic cutoff by ROC analysis was 3.88 and 1.04, respectively. Diagnostic performance was better with ${ }^{18} \mathrm{~F}-\mathrm{FDG} /{ }^{68} \mathrm{Ga}$-DOTATATE than with ${ }^{18} \mathrm{~F}-\mathrm{FDG}$ alone. significantly higher than that of normal pituitary tissue $(2.5 \pm 1.1, P<0.01)$. The ${ }^{68} \mathrm{Ga}$-DOTATATE $\mathrm{SUV}_{\max }$ was $3.0 \pm 1.1$, significantly lower than that of normal pituitary tissue $(5.5 \pm 1.7$, $P<0.01)$. The diagnoses were confirmed by surgical and pathologic findings (Table 1).

\section{Uptake in Confirmed Adenoma}

The ${ }^{18}$ F-FDG SUV $_{\max }$ of the 27 confirmed adenomas that underwent transsphenoidal adenomectomy was $6.5 \pm 3.6$, significantly higher than that of normal pituitary tissue $(2.9 \pm 1.1, P<0.01)$. The ${ }^{68}$ Ga-DOTATATE SUV $\max$ was $3.5 \pm 2.1$, significantly lower than that of normal pituitary tissue $(5.9 \pm 2.7, P<0.01)$.

\section{Uptake Ratio in Adenoma Versus Normal Tissue}

The ${ }^{18} \mathrm{~F}$-FDG/ ${ }^{68} \mathrm{Ga}$-DOTATATE $\mathrm{SUV}_{\max }$ ratios were $2.3 \pm 1.3$ in primary adenoma, $2.3 \pm 1.7$ in recurrent adenoma, and $2.3 \pm$ 1.5 in all confirmed cases of adenoma. All 3 ratios were significantly higher than those in normal pituitary tissue $(0.6 \pm 0.3$ $[P<0.01], 0.5 \pm 0.2[P<0.05]$, and $0.6 \pm$ $0.3[P<0.01]$, respectively; Supplemental Fig. 2).

\section{ROC Curve in Differentiation of Adenoma from Normal Tissue}

The area under the ROC curve was analyzed for ${ }^{18} \mathrm{~F}-\mathrm{FDG} \mathrm{SUV}_{\max }$ and ${ }^{18} \mathrm{~F}$ FDG $/{ }^{68} \mathrm{Ga}$-DOTATATE $\mathrm{SUV}_{\max }$ ratio in adenoma and normal pituitary tissue (Fig. 2). The best result was for the ratio. The optimal diagnostic cutoffs according to ROC analysis were 1.04 for the ratio and 3.88 for ${ }^{18} \mathrm{~F}$-FDG SUV $\max$ alone. With a cutoff of 1.04 for the ratio, the resulting sensitivity, specificity, and accuracy for discriminating between adenoma and normal pituitary tissue were $88.9 \%, 96.3 \%$, and $92.6 \%$, respectively. With a cutoff of 3.88 for ${ }^{18}$ F-FDG $\mathrm{SUV}_{\text {max }}$ alone, the respective percentages were $70.4 \%, 85.2 \%$ and $77.8 \%$.

\section{DISCUSSION}

MRI is the mainstay of assessing pituitary adenoma, which can be identified by criteria such as typical MRI features, a focus of low enhancement, remodeling of the pituitary sella floor, and deformity of the gland contour (16). Although surgical exploration of the pituitary fossa after positive MRI findings has been shown to confirm adenoma in $81 \%-88 \%$ of patients $(17,18)$, many hormone-secreting pituitary microadenomas are undetectable by present MRI technology. Evaluation of the pituitary gland and residual pituitary adenoma 
using MRI becomes much more difficult after surgery because of anatomic alterations and implant artifacts. The sensitivity of contrast-enhanced MRI of the pituitary can be marginally increased by acquiring a dynamic sequence in the first 1-2 min after contrast injection, but this technique has not been proven to increase the efficacy of MRI in pituitary adenoma $(19,20)$. Our study found a detection sensitivity of $47 \%$ and $39 \%$ in primary and recurrent pituitary microadenoma, respectively, using a $0.05 \mathrm{mmol} / \mathrm{kg}$ dose of gadopentetate dimeglumine, and a detection sensitivity of $37 \%$ and $50 \%$, respectively, using a $0.1 \mathrm{mmol} / \mathrm{kg}$ dose.

The pituitary gland does not normally accumulate ${ }^{18} \mathrm{~F}-\mathrm{FDG}$ and therefore is not ordinarily visible at high contrast on ${ }^{18} \mathrm{~F}-\mathrm{FDG}$ PET scans. In recent years, several reports have indicated that most pituitary adenomas can accumulate ${ }^{18} \mathrm{~F}-\mathrm{FDG}$ even if they are benign $(8,21)$. There is also evidence that ${ }^{18} \mathrm{~F}$-FDG PET/CT is able to detect pituitary adenoma with a higher sensitivity than contrast-enhanced MRI, especially in patients with a small lesion or with potential recurrence after transsphenoidal adenomectomy (22).

In this study, we showed that microadenomas that were previously undetectable or equivocal on contrast-enhanced MRI could be definitively detected by ${ }^{18} \mathrm{~F}-\mathrm{FDG}$ PET/MRI. The optimal diagnostic cutoff for ${ }^{18} \mathrm{~F}-\mathrm{FDG} \mathrm{SUV}_{\max }$ according to ROC analysis was 3.88 . With the combined use of ${ }^{68} \mathrm{Ga}-$ DOTATATE PET/MRI and ${ }^{18} \mathrm{~F}$-FDG PET/MRI, pituitary adenoma $\left({ }^{18} \mathrm{~F}-\mathrm{FDG}\right.$-positive, ${ }^{68} \mathrm{Ga}$-DOTATATE-positive $)$ could be well differentiated from normal pituitary tissue $\left({ }^{18} \mathrm{~F}-\mathrm{FDG}-\right.$ negative, ${ }^{68} \mathrm{Ga}$-DOTATATE-positive). In semiquantitative analysis, there were significant differences in ${ }^{18} \mathrm{~F}-\mathrm{FDG}$ and ${ }^{68} \mathrm{Ga}$-DOTATATE $\mathrm{SUV}_{\max }$ between pituitary adenoma and normal pituitary tissue. The significance was more remarkable when the ${ }^{18} \mathrm{~F}-\mathrm{FDG} /{ }^{68} \mathrm{Ga}$-DOTATATE SUV $\max$ ratio was applied. We found a ratio cutoff of 1.04 to be optimal for differentiating between pituitary adenoma and normal pituitary tissue. However, there is no defined consensus or published data for the interpretation of the ${ }^{18} \mathrm{~F}-\mathrm{FDG} /{ }^{68} \mathrm{Ga}$-DOTATATE $\mathrm{SUV}_{\max }$ ratio in pituitary adenoma and normal pituitary tissue. Thus, we believe our data can serve as a reference for routine clinical practice.

With the time-of-flight PET/MRI system used in our study, the simultaneous acquisition of PET and MR images allowed for a rapid, 1-stop diagnosis of patients. The high-resolution PET/ MR images were flawless and without artifacts, clearly displaying the relationship among pituitary adenoma, normal pituitary tissue, periphery blood vessels, and other structures. The dual-tracer PET/MR images enabled better diagnosis and characterization of the adenoma than single-tracer images, added diagnostic confidence, and helped guide the adenomectomy that followed.

The major limitation of our study was the small number of cases, as the cutoff differentiated best between pituitary adenoma and normal pituitary tissue in this small cohort but is not universally applicable. However, as a pilot study, its result is enough to merit further investigation. A possible confounder in comparisons of $\mathrm{SUV}_{\max }$ is the partial-volume effect, in view of the small size of the pituitary adenomas in these patients and the small pituitary remnants in some of them after surgery. When a microadenoma is at the core of the pituitary gland, the value of ${ }^{68} \mathrm{Ga}$-DOTATATE imaging is limited by the difficulty of demarcating the tumor against the high-uptake background of normal pituitary tissue. In addition, a multitracer approach complicates the diagnostic workup. In clinical application, ${ }^{18} \mathrm{~F}-\mathrm{FDG}$ PET/MRI is normally enough to make a diagnosis, especially when the adenoma is large. The multitracer approach presented in this study would be used to increase confidence only when diagnosis is complicated by situations such as an MRI-negative or -equivocal hormone-producing pituitary microadenoma or a relapse early after surgery.

\section{CONCLUSION}

This preliminary study showed that the combination of the high sensitivity and specificity of PET with the detailed softtissue display of MRI provides an ideal tool for detecting hormone-producing pituitary microadenoma. In addition, a dual-tracer approach using ${ }^{18} \mathrm{~F}$-FDG and ${ }^{68} \mathrm{Ga}$-DOTATATE was helpful for distinguishing pituitary adenoma from normal pituitary tissue, especially in patients with complex structural changes after surgery. This multitracer, multimodality imaging method increased diagnostic confidence and guided surgery in patients with hormone-secreting pituitary microadenoma.

\section{DISCLOSURE}

This study was supported by the Peking Union Medical College Scholar project and partly by a CAMS Major Collaborative Innovation Project (2016-I2M-1-011) and Welfare Research Funding for Public Health Professionals (201402001). No other potential conflict of interest relevant to this article was reported.

\section{ACKNOWLEDGMENT}

We express our sincerest thanks to Prof. Heinrich R. Schelbert for enlightening discussions, review of the language, and encouragement to complete our investigation.

\section{REFERENCES}

1. Molitch ME. Nonfunctioning pituitary tumors and pituitary incidentalomas. Endocrinol Metab Clin North Am. 2008;37:151-171.

2. Elster AD. Modern imaging of the pituitary. Radiology. 1993;187:1-14.

3. Kremer P, Forsting M, Ranaei G, et al. Magnetic resonance imaging after transsphenoidal surgery of clinically non-functional pituitary macroadenomas and its impact on detecting residual adenoma. Acta Neurochir (Wien). 2002;144:433443.

4. Rajaraman V, Schulder M. Postoperative MRI appearance after transsphenoidal pituitary tumor resection. Surg Neurol. 1999;52:592-598.

5. Kremer P, Forsting M, Hamer J, et al. MRI of residual tumor tissue after transsphenoidal surgery of hormone-inactive pituitary macroadenomas: a prospective study. Acta Neurochir Suppl. 1996;65:27-30.

6. Di Maio S, Biswas A, Vezina JL, et al. Pre- and postoperative magnetic resonance imaging appearance of the normal residual pituitary gland following macroadenoma resection: clinical implications. Surg Neurol Int. 2012; $3: 67$.

7. Seok H, Lee EY, Choe EY, et al. Analysis of ${ }^{18} \mathrm{~F}$-fluorodeoxyglucose positron emission tomography findings in patients with pituitary lesions. Korean J Intern Med. 2013;28:81-88.

8. De Souza B, Brunetti A, Fulham MJ, et al. Pituitary microadenomas: a PET study. Radiology. 1990;177:39-44.

9. Schneider C, Schlaak M, Bludau M, et al. ${ }^{68} \mathrm{Ga}$-DOTATATE-PET/CT positive metastatic lymph node in a 69-year-old woman with Merkel cell carcinoma. Clin Nucl Med. 2012;37:1108-1111. 
10. Buchmann I, Henze M, Engelbrecht S, et al. Comparison of ${ }^{68}$ Ga-DOTATOC PET and ${ }^{111}$ In-DTPAOC (OctreoScan) SPECT in patients with neuroendocrine tumours. Eur J Nucl Med Mol Imaging. 2007;34:1617-1626.

11. Gayana S, Mittal BR, Bhattacharya A, et al. ${ }^{68}$ Ga-DOTATATE PET/CT imaging in carotid body tumor. Clin Nucl Med. 2013;38:e191-e193.

12. Kabasakal L, Demirci E, Ocak M, et al. Comparison of ${ }^{68} \mathrm{Ga}$-DOTATATE and ${ }^{68} \mathrm{Ga}$-DOTANOC PET/CT imaging in the same patient group with neuroendocrine tumours. Eur J Nucl Med Mol Imaging. 2012;39:1271-1277.

13. Klinaki I, Al-Nahhas A, Soneji N, et al. ${ }^{68}$ Ga DOTATATE PET/CT uptake in spinal lesions and MRI correlation on a patient with neuroendocrine tumor: potential pitfalls. Clin Nucl Med. 2013;38:e449-e453.

14. Lapa C, Lohr M, Bluemel C, et al. Primary central nervous system lymphoma and meningioma in DOTATATE PET/CT. Clin Nucl Med. 2013; 38:994-995.

15. Zhao X, Xiao JQ, Xing B, et al. Comparison of ${ }^{68}$ Ga-DOTATATE to ${ }^{18}$ F-FDG uptake is useful in the differentiation of residual or recurrent pituitary adenoma from the remaining pituitary tissue after transsphenoidal adenomectomy. Clin Nucl Med. 2014;39:605-608.

16. Sahdev A, Reznek RH, Evanson J, et al. Imaging in Cushing's syndrome. Arq Bras Endocrinol Metabol. 2007;51:1319-1328.
17. Testa RM, Albiger N, Occhi G, et al. The usefulness of combined biochemical tests in the diagnosis of Cushing's disease with negative pituitary magnetic resonance imaging. Eur J Endocrinol. 2007;156:241248.

18. Salenave S, Gatta B, Pecheur S, et al. Pituitary magnetic resonance imaging findings do not influence surgical outcome in adrenocorticotropin-secreting microadenomas. J Clin Endocrinol Metab. 2004;89:33713376.

19. Bartynski WS, Lin L. Dynamic and conventional spin-echo MR of pituitary microlesions. AJNR Am J Neuroradiol. 1997;18:965-972.

20. Tabarin A, Laurent F, Catargi B, et al. Comparative evaluation of conventional and dynamic magnetic resonance imaging of the pituitary gland for the diagnosis of Cushing's disease. Clin Endocrinol (Oxf). 1998;49:293300 .

21. Bergström M, Muhr C, Lundberg PO. PET as a tool in the clinical evaluation of pituitary adenomas. J Nucl Med. 1991;32:610-615.

22. Chittiboina P, Montgomery BK, Millo C, et al. High-resolution ${ }^{18}$ F-fluorodeoxyglucose positron emission tomography and magnetic resonance imaging for pituitary adenoma detection in Cushing disease. J Neurosurg. 2015;122:791797.

\section{Erratum}

In the Newsline article "Report Targets Acceleration of Cancer Research to Meet Moonshot Goals" ( $J$ Nucl Med. 2018;59:14N), Dr. Sanjiv Sam Gambhir was inadvertently left out of the list of collaborators. The list of collaborators should read "A number of SNMMI members served as commissioners and contributed to development of the report. They include SNMMI immediate-past-president Sally Schwarz, MS, RPh, BCNP; SNMMI past-president Hossein Jadvar, MD, PhD, MPH, MBA; David Mankoff, MD, PhD; Martin G. Pomper, MD, PhD; Richard Wahl, MD; and Sanjiv Sam Gambhir, MD, PhD." We regret the error. 